\title{
THE DEVELOPMENT OF ASSISTIVE COURSEWARE FOR YOUNG LOW VISION LEARNERS BASED ON MULTIPLE INTELLIGENCE THEORY
}

\author{
A. Nurulnadwan ${ }^{1 *}$, A. M. Ariffin ${ }^{2}$, and S. Siti Mahfuzah ${ }^{2}$ \\ ${ }^{1}$ Department of Research, Industrial Linkages, and Alumni, Universiti Teknologi MARA, \\ 23000 Dungun Terengganu, Malaysia \\ ${ }^{2}$ School of Multimedia Technology and Communication, Universiti Utara Malaysia 06010 \\ Sintok, Kedah, Malaysia
}

Published online: 17 October 2017

\begin{abstract}
This paper reports an ongoing study regarding the development of Assistive Courseware (AC) which specifically designed catering to the needs of low vision learners in learning activities. Previous literatures state that most of the available digital interactive learning content means too little to them, particularly in terms of content presentation. Therefore, this study solves the problem by developing an assistive courseware (AC), which is named as AC for Low Vision Learners (AC4LV). The AC was developed by utilizing Multiple Intelligence (MI) theory as guidance. In addition, three basic steps, which are pre-production, production, and post-production have been utilized in developing the AC. As a result, an AC4LV based on MI theory was successfully produced. Future works of this study is to test the experience of using AC4LV among the low vision learners in terms of it usefulness.
\end{abstract}

Keywords: interaction design; child-computer interaction; assistive technology; low vision; multiple intelligence theory.

Author Correspondence, e-mail: nuruln746@tganu.uitm.edu.my

doi: http://dx.doi.org/10.4314/jfas.v9i5s.69 


\section{INTRODUCTION}

Low vision learners are not similar with sighted learners. With the restrictions in their seeing, low vision learners have to fully utilize their other senses in their learning activities to compete with their sighted peers [1] [23]. Unfortunately, most of the learning materials do not support them and usually contain limited availability [2] [22]. By utilizing similar learning materials (i.e. text book and typical courseware (TC)) with sighted students, and assisted with Assistive Technology (AT) (i.e. Close Circuit Television (CCTV), magnifying glass, screen reader, and screen magnification) [3] were actually problematic for them at most of the time [4] particularly for children [5]. For the reason they do not want to look different between their sighted peers and sometimes they also missing the equipment [6]. In regards to that, an observation conducted at Special Primary School of Visual Impairment, Penang Malaysia found that the low vision learners have to highly concentrate on the audio in order to get the information displayed on the online TC (Fig. 1). All these factors make their learning activities too complicated and have no pleasure [7].

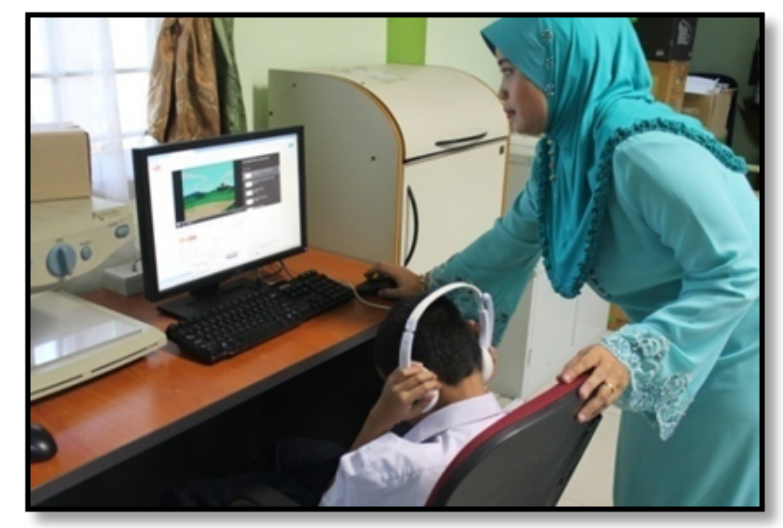

Fig.1. Low vision learner using online TC with the teachers' help

Most of the applications created to assist them in learning are in the form of software and hardware, which are also known as assistive learning tools [3]. Also, most of this type of technologies requires the low vision learners to have certain technical skills to operate it. This is totally not appropriate for the low vision learners particularly for children to learn at their own pace [8]. Furthermore, available content application means too little to them. This is because most of the content applications are created for fully-sighted students [9]. They are different, in which the fully-sighted students are visual learners while low vision learners are 
audible learners [10]. With the multiple pages, iconic menus, fancy font face, and unsuitable font size and animations, the low vision learners face difficulties in their learning and finally get frustrated [11]. Also, previous studies [3] [7] [12] [13] [14] indicate that interactive digital learning applications that are specifically designed to cater the needs of low vision learners in learning particularly in terms of information accessibility, navigationability, and pleasurability aspects is insufficiently explored. It means their needs are not adequately factored into the design of digital learning contents [9] [15]. In fact, these three aspects are the main problems that are currently faced by the low vision learners [9] [16]. Table 1 summarizes the problems, method of teaching, and materials that are currently used in teaching and learning of low vision learners.

Table 1. Current problems and methods of teaching and learning for low vision learners

\begin{tabular}{|l|l|}
\hline Details & Problems \\
\hline \multirow{2}{*}{ Low vision learners } & $\begin{array}{l}\text { - The low learners face difficulties in grasping the knowledge } \\
\text { delivered through conventional teaching method and } \\
\text { available courseware. } \\
\text { and navigationability. }\end{array}$ \\
\hline \multirow{2}{*}{ Teaching method } & $\begin{array}{l}\text { - Due to facing a lot of difficulties, these influence them not } \\
\text { to have pleasurability in learning activities. } \\
\text { students which are conducted in class or computer lab. }\end{array}$ \\
\hline Material & $\begin{array}{l}\text { - Typical text book, flash cards, book with pictures (i.e. big } \\
\text { size), demo from the teachers, Close Circuit Television } \\
\text { (CCTV), magnifying glass, online TC (i.e. nursery rhymes). }\end{array}$ \\
\hline
\end{tabular}

The details in Table 1 indicate that the needs for educational content application for low vision learners are urgently necessary. Therefore, this study is carried out, with special aims to achieve the following objectives: (i) to identify the needs of low vision learners in learning, (ii) to review the previous literatures related to MI theory, and (iii) to develop a courseware that is specifically 
designed to cater the needs of low vision learners based on MI theory which is named as AC4LV.

Having identified the needs of the low vision learners in learning, it is not significant for this study to not refer to any learning theory prior to develop the courseware since learning theories act as the root in developing any instructional materials including courseware. Of many types of learning theories, MI proposed by Gardner and Hatch, (1989) is considered as one of the significant learning theories. Prior to developing the AC4LV, this study provides some reviews and elicited studies related to the intended theory, which is discussed in the following subsection.

\section{REVIEWS ON MULTIPLE INTELLIGENCE (MI) THEORY}

The theory of MI was proposed by Howard Gardner in 1983 and further updated in 1993 and 2000. MI has produced a great implication to the world of education [7]. This can be seen when many educational institution including pre-schools and elementary schools have utilized it as their philosophy. In fact, it is not just a philosophy but all the nine intelligence put emphasis on the learning content and its intra-relation [13]. On top of that, the MI theory enables educators to develop their repertoire of methods, equipment, and approach beyond those that are commonly used in the conventional teaching. Accordingly, this could develop the children to be confident with their natural abilities.

In conjunction, several projects have been found applying MI theory into their applications. As an example [18] proposed personalized adaptive e-learning system based on multiple intelligence of the learners. Another work is the development of serious educational game based on MI theory by [19]. This applications utilize the MI theory to help game designers to create games that are better tailored to particular intelligences, to get the better gameplay experience and learning outcome.

In relation with that, the development of AC4LV also considers the nine MI theory (Table 2) for the reason that it is important to reveal the implicit intelligence and ability of low vision children in attempt to make AC4LV useful. 
Table 2. Multiple intelligence theory

\begin{tabular}{|c|c|}
\hline Intelligence & Description \\
\hline $\begin{array}{l}\text { Verbal-Linguistic } \\
\text { Intelligence }\end{array}$ & $\begin{array}{l}\text { The ability to learn languages in spoken and written, } \\
\text { and the capacity to use that language to accomplish } \\
\text { certain goals. }\end{array}$ \\
\hline $\begin{array}{l}\text { Mathematical-Logical } \\
\text { Intelligence }\end{array}$ & $\begin{array}{l}\text { The ability to analyze problems logically, carries out } \\
\text { mathematical operations, and investigates issues } \\
\text { scientifically. }\end{array}$ \\
\hline $\begin{array}{l}\text { Visual-Spatial } \\
\text { Intelligence }\end{array}$ & $\begin{array}{l}\text { The ability to recognize and manipulate patterns of } \\
\text { wide space as well as patterns of more confined areas. }\end{array}$ \\
\hline $\begin{array}{l}\text { Intrapersonal } \\
\text { Intelligence }\end{array}$ & $\begin{array}{l}\text { The ability to understand oneself, to have an effective } \\
\text { working of oneself including one's own desire, fears } \\
\text { and ability to use such information effectively in } \\
\text { regulating one's own life. }\end{array}$ \\
\hline $\begin{array}{l}\text { Bodily-Kinesthetic } \\
\text { Intelligence }\end{array}$ & $\begin{array}{l}\text { The ability to use one's whole body or parts of the body } \\
\text { to solve problems. }\end{array}$ \\
\hline Interpersonal & $\begin{array}{l}\text { The ability to understand the intentions, motivations } \\
\text { and desires of other people and ability to work } \\
\text { effectively with others. }\end{array}$ \\
\hline Naturalist Intelligence & $\begin{array}{l}\text { The ability to recognize and classifies of numerous } \\
\text { species of flora and fauna of his or her environment. }\end{array}$ \\
\hline Musical-Rhythmic & $\begin{array}{l}\text { The ability to have skills in performance, composition } \\
\text { musical patterns and appreciation of musical patterns. }\end{array}$ \\
\hline Existential & $\begin{array}{l}\text { The ability to have sensitivity to existence surrounded } \\
\text { complex issues and curiosity to ask deep questions. }\end{array}$ \\
\hline
\end{tabular}

MI theory is a perfect theory for the development of children's ability because the main subject of this study is low vision children. In the context of this study, all principles are applicable to be applied in AC4LV at a time since AC4LV is a multimedia learning content application. However, the connection must be carefully applied to ensure the application is 
useful in terms of information accessibility, navigationability, and pleasurability for the low vision learners. In response to that, the next section discusses on methodology utilized in conducting this study.

\section{METHODOLOGY}

In this study a series of activities were carried out, as shown illustratively in Fig. 2. The figure explains that this study involves three phases of activities which are (i) requirement analysis (ii) reviews on literatures, and (iii) prototype development [20]. The activities involved in the first phase are requirement analysis, which implicates that previous studies regarding the problems faced by the low vision learners were reviewed. Also, they were interviewed and their learning activities were observed in order to identify their needs in learning. Phase two involves reviews and elicitation on literatures in which the documents related to MI theory were studied. From this phase, data regarding the principles of MI theory were reviewed, and then the second objective of the study was achieved. The third phase is prototype development, in which the development process as illustrated in Fig. 3 were employed based on the data gathered in phases one and two. At this stage, this study has achieved its third objective. Having finished the third phase, the whole objective of this study is achieved. Going in-depth into the development process of the AC4LV, it involves three phases which are pre-production, production, and post production (Fig. 4). In the first phase, 10 steps were implemented. In developing the AC4LV, users and experts were involved before the development commenced. At this phase, requirements of users were investigated by interviewing teachers regarding the needs of the low vision learners to suit with the actual content of AC4LV. Also, the low vision learners were involved in gathering inputs and comments in terms of the design of the AC4LV. 


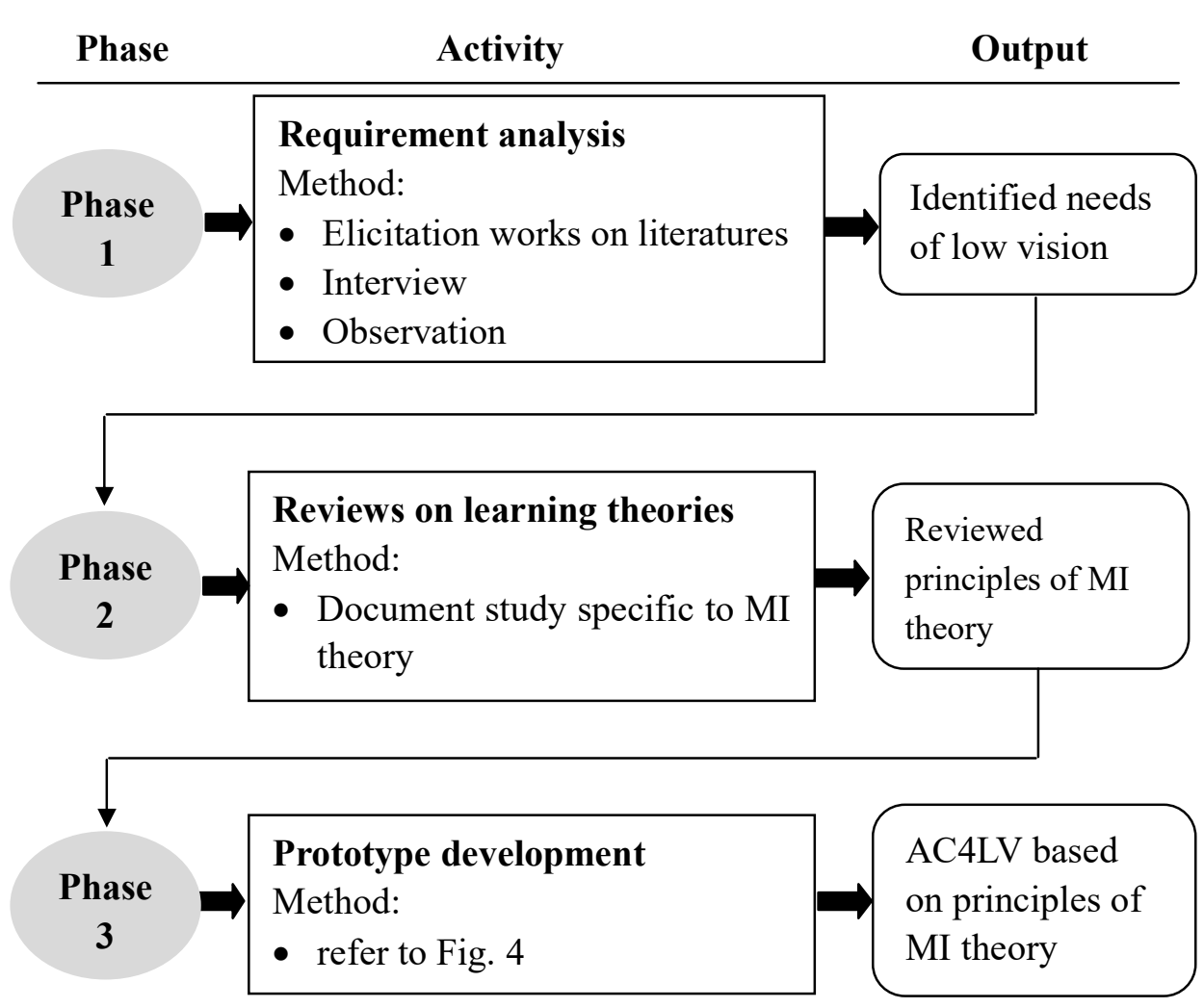

Fig.2. Summary of research activity

Reviewed principles of MI theory were utilized as a design guideline prior to beginning the interview. All inputs are important in preparing the script and storyboard of the AC4LV. This is called as User-Centered Design (UCD) approach [24] as demonstrated in Fig. 4 and 5. Having finished the 10 steps in pre-production phase, the development of the AC4LV began by utilizing Adobe Flash as the basic of the development tool. Meanwhile, Sound Forge was used to record and edit the sound, and Adobe Illustrator was utilized to design all the characters. In the post-production phase, editing, and quality checking were performed, which also involved the actual users and their teachers. It was done until they were satisfied and finally the AC4LV was packaged in the form of DVD prior to testing the experience of using it in the future works of this study. 


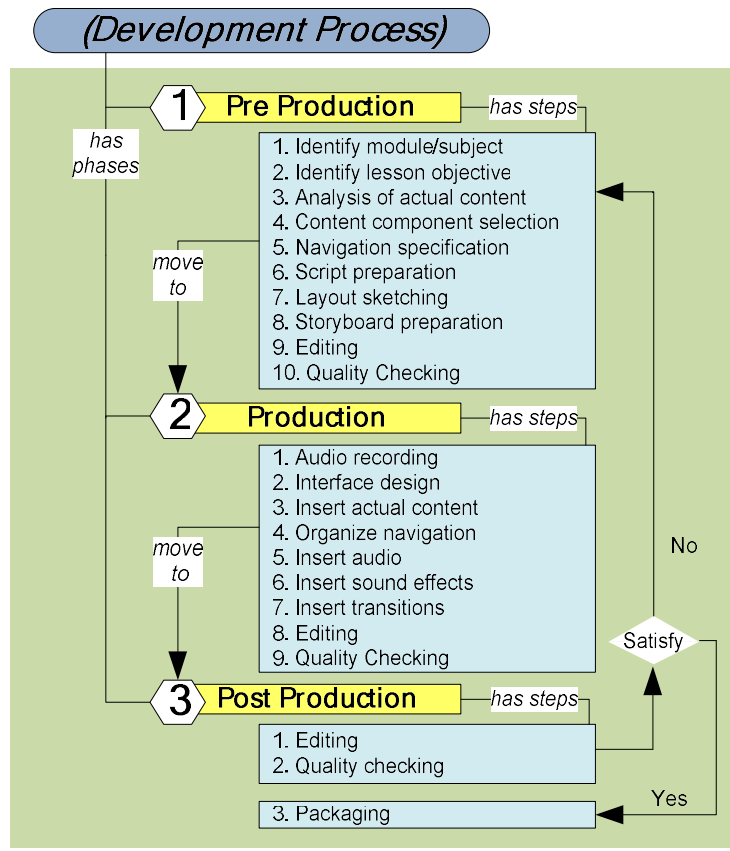

Fig.3. Development process of AC4LV

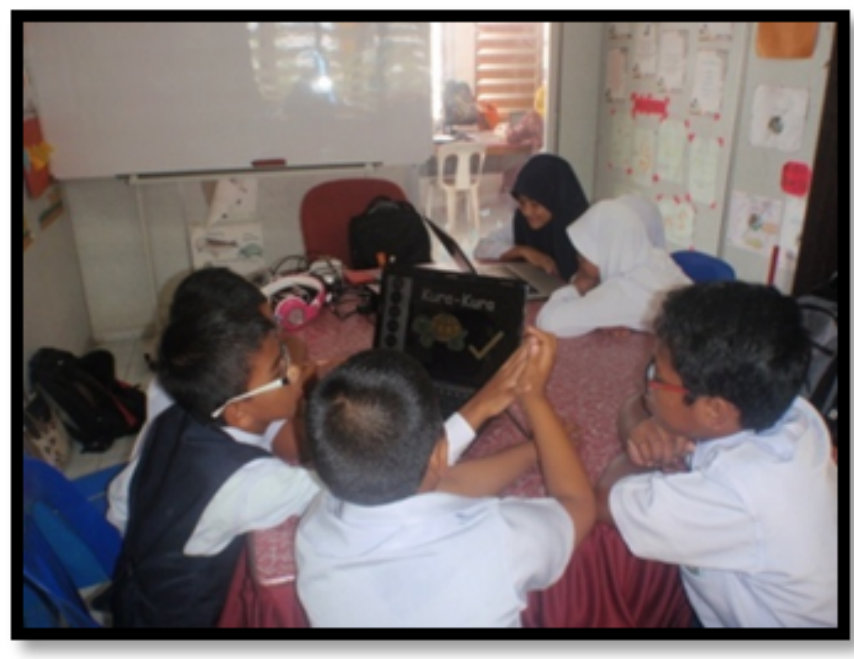

Fig.4. Applying UCD approach with low vision learners 


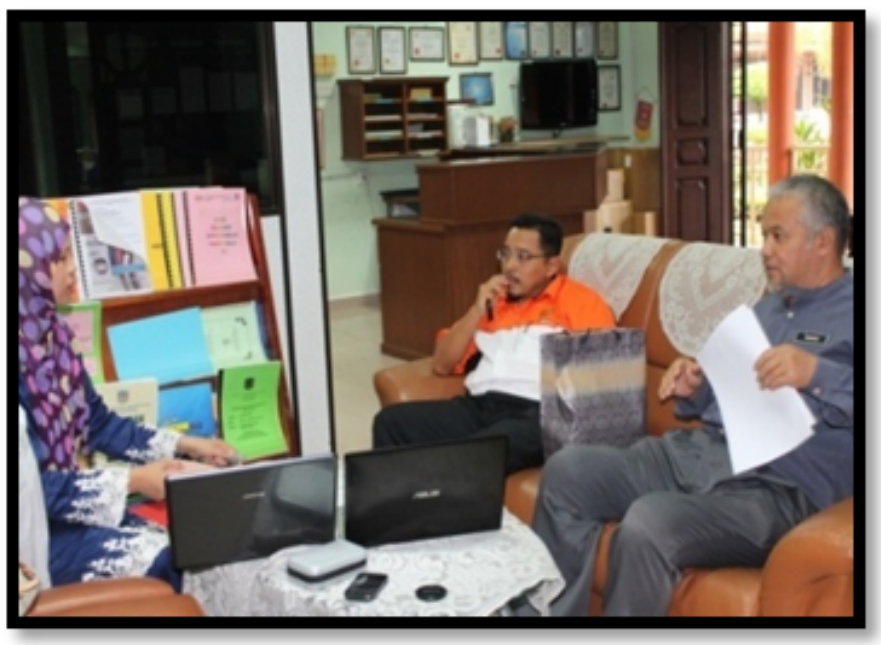

Fig.5. Applying UCD approach with teachers

\section{RESULT AND DISCUSSION}

MI theory has been utilized as a reference and guidance in designing the content of the AC4LV based on the identified user needs. Therefore, this section discusses on the findings gathered in phase three on how the principles of MI theory are applied in the AC4LV based on the low vision learners' needs in information accessibility, navigationability, and pleasurability. The results are discussed in detail in the next section together with the snapshots of the prototype.

\subsection{MI theory connected to AC4LV based on Low Vision Learners Learning Needs}

\subsubsection{Information Accessibility}

Information accessibility refers to the characteristics of the AC4LV that enable the low vision learners to capture the learning content presented to them. The principles of MI theory adapted for supporting the information accessibility aspect are as follow:

Verbal-Linguistic - In AC4LV, the linguistic aspects are provided in written and auditory form such as in lecturing and instructions by providing auditory explanation and text-based information. Also, the low vision learners could learn spelling through the fill in the blank activities. This embeds both types of intelligence (Fig. 6). 


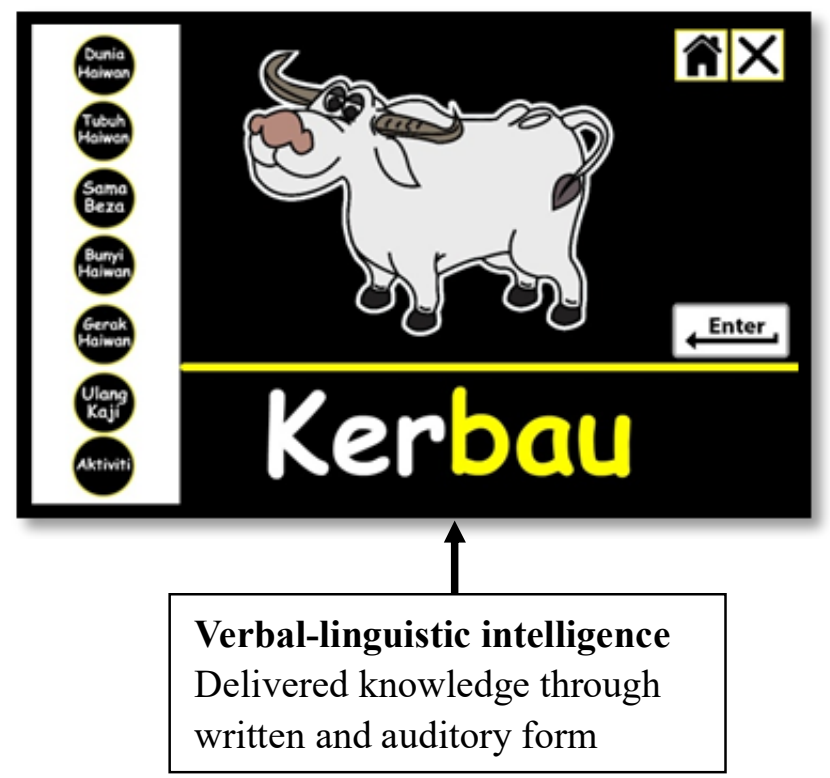

Fig.6. Verbal - linguistic intelligence mapped to AC4LV

Visual-spatial - Accessible visual content in various formats such as texts, graphics, and animations makes the low vision learners actively interacting with the spaces provided in the AC4LV (Fig. 7).

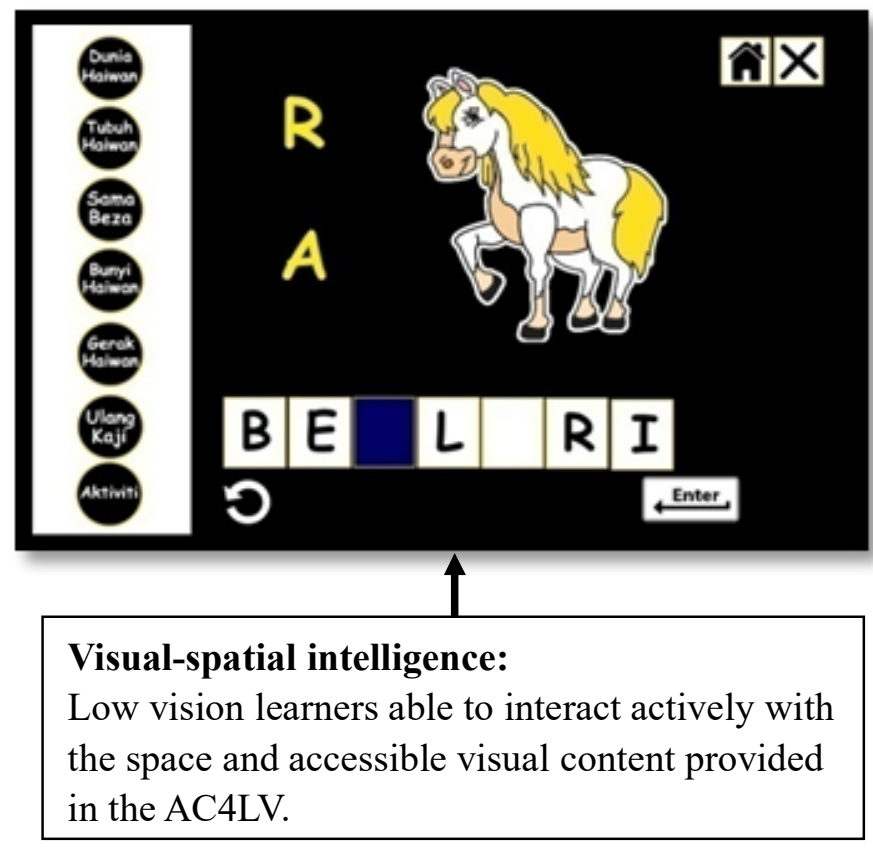

Fig.7. Visual - spatial intelligence mapped to AC4LV 


\subsubsection{Navigationability}

Navigationability means the characteristics of the AC4LV that are able to assist the low vision learners in navigating the courseware. The principle of MI theory adapted for supporting the navigationability are as follow:

Bodily-kinesthetic - AC4LV offers keyboard-based interaction [21], which could assist the low vision learners to interact with the courseware through the part of their body movement such as hands (Fig. 8).

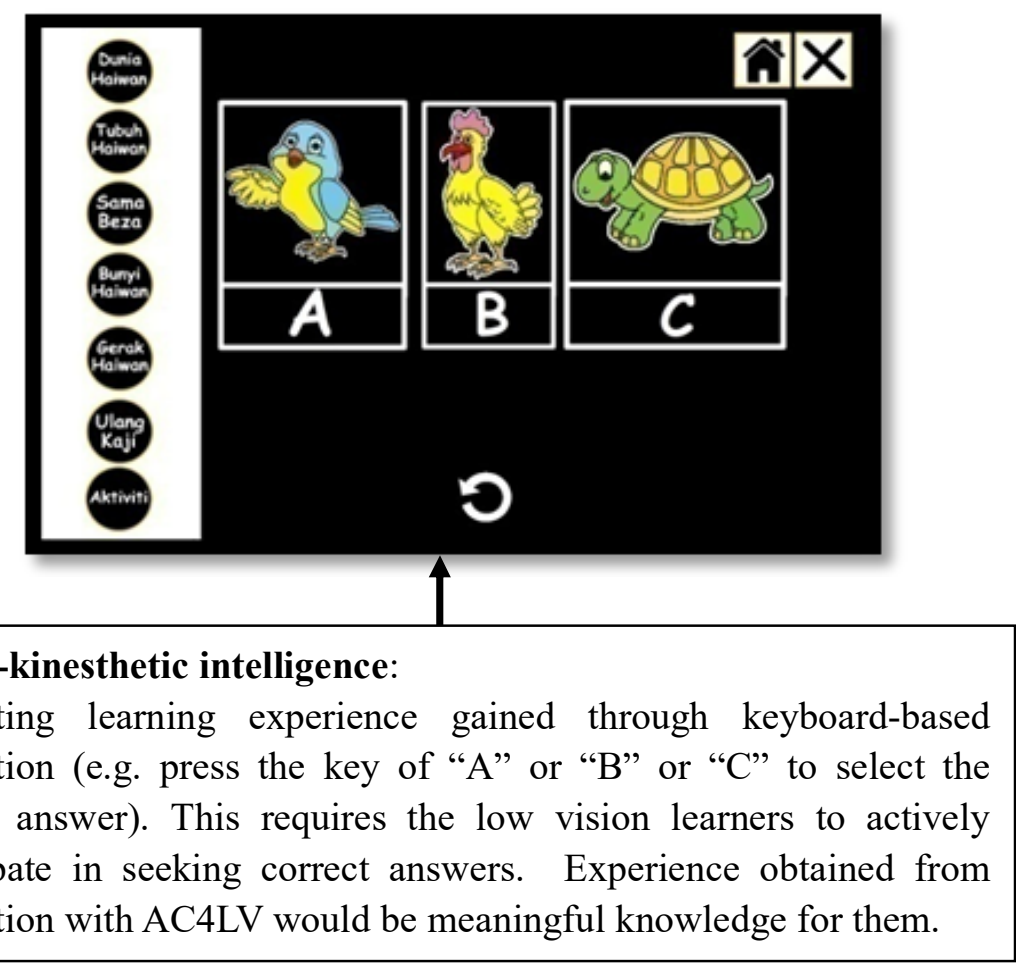

Fig.8. Bodily-kinesthetic intelligence mapped to AC4LV

\subsubsection{Pleasurability}

Pleasurability in the AC4LV means the characteristics of AC4LV that make the low vision learners feel fun, amused, enjoy, curiosity, and release as well as have no pressure during learning activities. This could be seen in the following principles:

Interpersonal- The learning content in the AC4LV including topics and activity influence the low vision learners to discuss with their peers when comes to the complex content or problem solving activities. Motivations and curiosity also could appear through discussion with peers 
(Fig. 9).

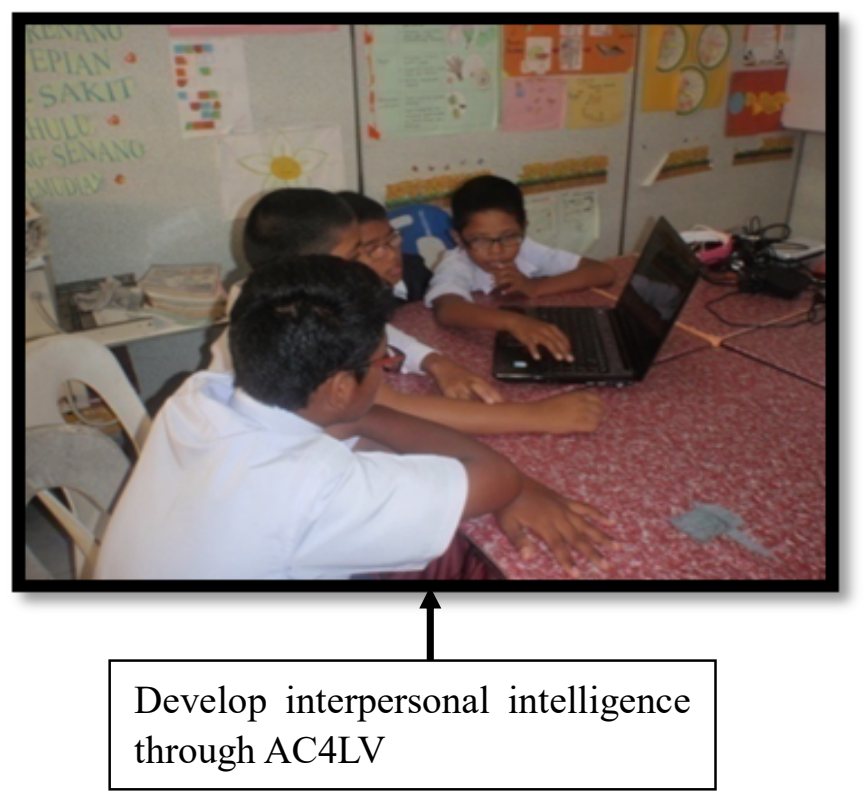

Fig.9. Interpersonal intelligence mapped to AC4LV

Intrapersonal - Easily accessed contents in the AC4LV encourage the low vision learners to monologue in the process of understanding the content. This means they enjoy the learning content (Fig. 10).

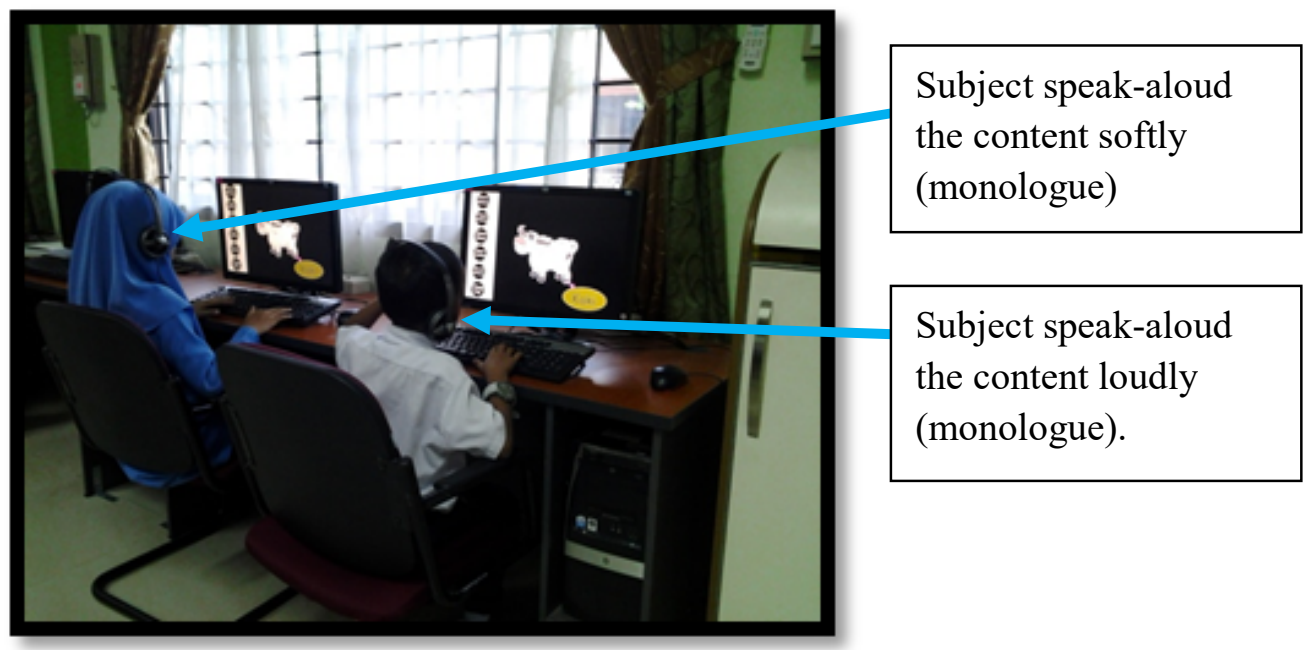

Fig.10. Interpersonal intelligence mapped to AC4LV

Musical - This aspect is embedded in the AC4LV by providing song, starting music, and sound effects to give fun elements to the low vision learners (Fig. 11). 


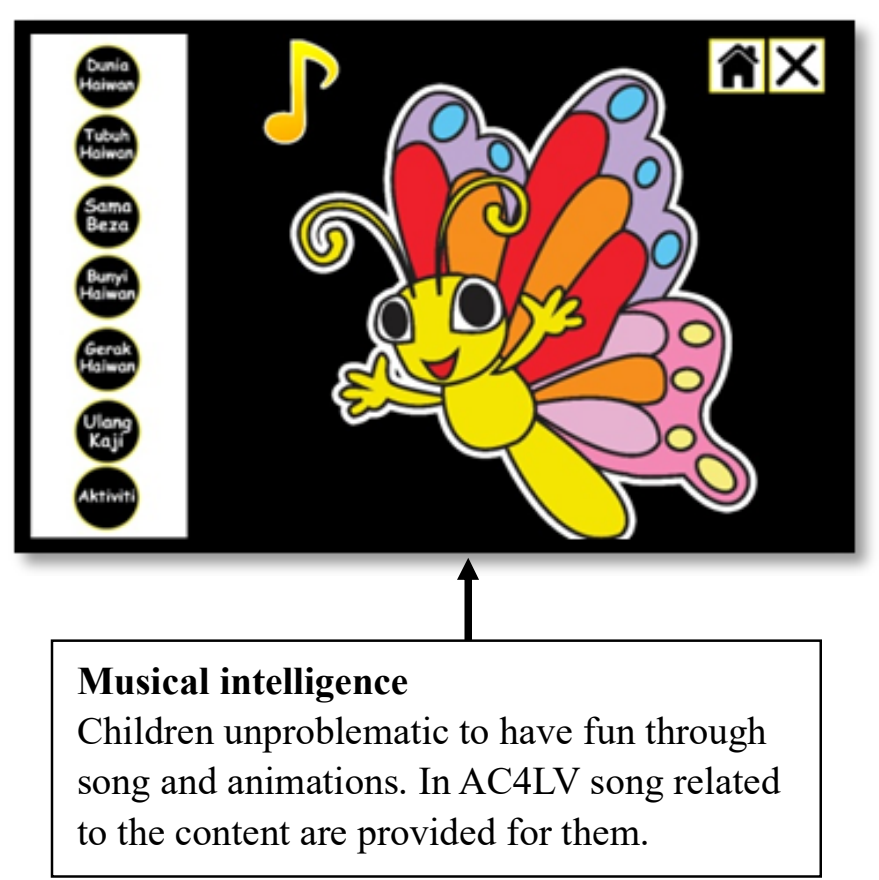

Fig. 11. Musical intelligence mapped to AC4LV

Naturalist - This concept provides experience in terms of numerous species of flora and fauna, which could be achieved in the actual content provided in the prototype. A part from that, accessible naturalist principle encourages the low vision learners to have no pressure in their learning activities (Fig. 12).

Existential - Having the accessible naturalist content in the AC4LV could influence the low vision learners to have the sensitivity to the existence of elements in their surroundings. This motivates them to ask deep questions. This means applying existential principle in the AC4LV could give confidence to the low vision learners in classroom as well as feeling enjoy in their learning activities (Fig. 12). 


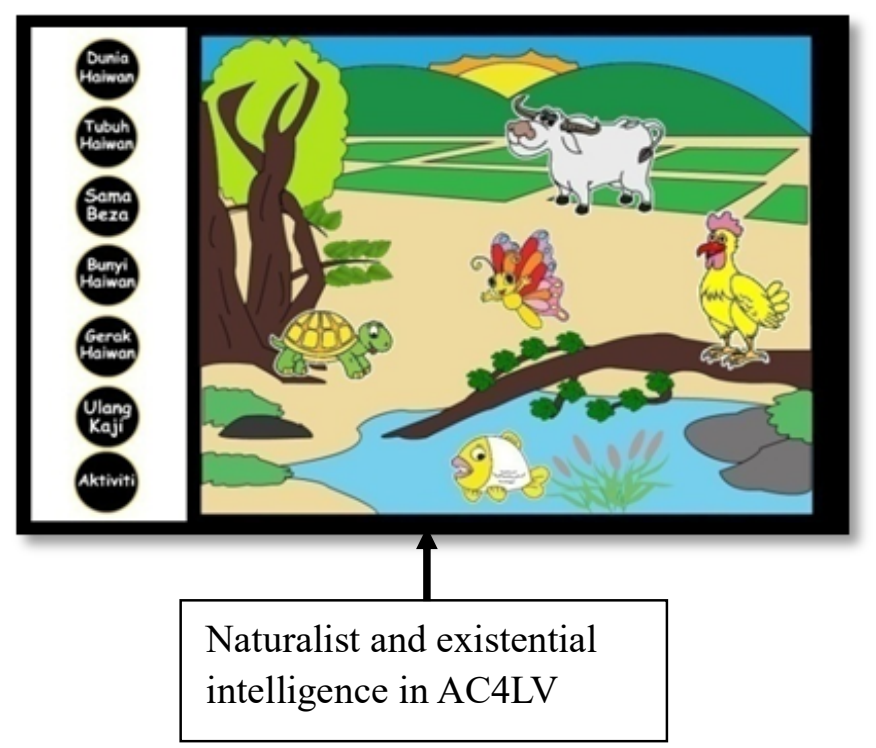

Fig.12. Naturalist and existential intelligence mapped to AC4LV

Logical - Multiple forms of accessible activities provided in the AC4LV force them to use logical thinking which means the low vision learners could think without any pressure in order to complete their learning activities compared to the TC, which are unsuitable to them (Fig. 13).

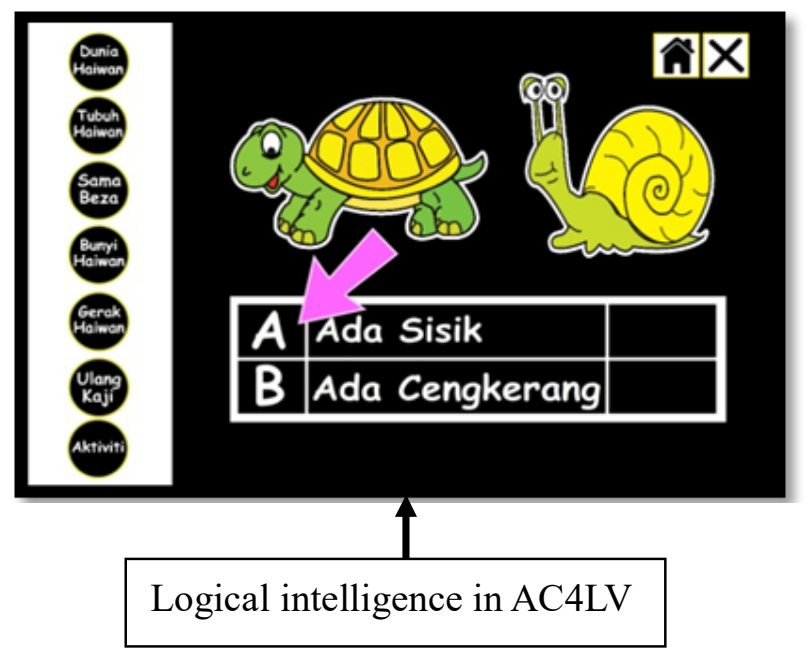

Fig.13. Logical intelligence mapped to AC4LV 


\section{CONCLUSION}

In overall, this study has achieved its objective to develop a courseware that is specifically designed for low vision learners based on MI theory by concerning the needs of low vision learners in learning. Through interviews and observations, it was found that information accessibility, navigationability, and pleasurability are the main aspects that have to be concerned by developers prior to developing a content application for low vision learners particularly courseware. Besides the user needs, it is significant for this study to consider MI theory as the guidance in designing the contents of the AC4LV as it is for low vision children. Findings of this study indicate that all principles of MI theory are applicable to be adapted in AC4LV as well as fulfill the user needs. In future, this study expects to test the experience of using AC4LV among the low vision learners from age nine to twelve in terms of information accessibility, navigationability, and pleasurability aspects.

\section{ACKNOWLEDGMENT}

The researchers wish to thank to Primary School of Jabi (Visual Impairment Integration) and Special Primary School of Alma (Visual Impairment), Malaysia for their cooperation participating in this study. This study also has been financed by Universiti Teknologi MARA and Ministry of Higher Education, Malaysia under IPTA's Academic Training Scheme (KPT (BS) 810117025346). Special thanks also goes to Universiti Utara Malaysia for providing research grant (PIBT-12837) and lab facilities (School of Multimedia Technology) to make this study run successfully. The authors gratefully acknowledge to these credibility organizations'.

\section{REFERENCES}

[1] Jafri R, Mohammed A, and Abid S. A tangible interface-based application for teaching tactual shape perception and spatial awarenesss sub-concepts to visually-impaired children. Procedia Manuf., 2015, 3, 5562-5569

[2] Wongkia W, Naruedomkul K, and Cercone N. i-Math: Automatic math reader for Thai blind and visually. Comput. Math. with Appl., 2012, 64(6):2128-2140

[3] Kim H K, Han S H, Park J, and Park J. The interaction experiences of visually impaired 
people with assistive technology: A case study of smartphones. Int. J. Ind. Ergon., 2016, 55, $22-33$

[4] Dursin A G. Information design and education for visually impaired and blind people. Procedia - Soc. Behav. Sci., 2012, 46, 5568-5572

[5] Mazella A, Albaret J M, and Picard D. Haptic-2D: A new haptic test battery assessing the tactual abilities of sighted and visually impaired children and adolescents with two-dimensional raised materials. Res. Dev. Disabil., 2016, 48, 103-123

[6] Khadka J, Ryan B, Margrain T H, Woodhouse J M, and Davies N, Listening to voices of children with a visual impairment: A focus group study. Br. J. Vis. Impair., 2012, 30(3): $182-196$

[7] Kocyigit N, Artar P S. A challenge: Teaching English to visually-impaired learners. Procedia - Soc. Behav. Sci., 2015, 199, 689-694

[8] Decker D M, Shaw J D, Boyes L, Tantillo D J, and Wedler H B. The value of safety and practi- cality: Recommendations for training disabled students in the sciences with a focus on blind and visually impaired students in chemistry laboratories. J. Chem. Heal. Saf., 2015, 23(1):5-11

[9] Yoon K, Dols R, Hulscher L, and Newberry T. An exploratory study of library website accessibility for visually impaired users. Libr. Inf. Sci. Res., 2016, 38(3):250-258

[10]Onishi J, Sakajiri M, Miura T, and Ono T. Terminal operation learning application for the screen reader users. In IEEE Int. Conf. Syst. Man, Cybernatics, 2015, pp. 2343-2348

[11] Jafri R, Aljuhani A M, and Ali S A. A tangible user interface-based application utilizing 3D-printed manipulatives for teaching tactual shape perception and spatial awareness sub-concepts to visually impaired children. Int. J. Child-Computer Interact., 2016

[12]Khaleel F L, Ashaari N S, Siti T, Tengku M, and Ismail A. Gamification elements for learning applications. Int. J. Adv. Sci. Eng. Inf. Technol., 2016, 6(6):868-874

[13]Ihmeideh F M. Assessment of children's digital courseware in light of developmentally appropriate courseware criteria. Br. J. Educ. Technol., 46(3):649-663

[14]Hussain N H, Siti T, Tengku M, Fadzilah S, and Noor M. Children 's interaction ability towards multi-touch gestures. Int. J. Adv. Sci. Eng. Inf. Technol., 2016 6(6):875-881

[15] Yurtay N, Yurtay Y, and Adak M F. An education portal for visually impaired. Procedia - 
Soc. Behav. Sci., 2015, 171, 1097-1105

[16]Nurulnadwan A, Ariffin A M, and Siti Mahfuzah S. Integrating multimedia learning theory in assistive courseware for low vision learners. J. Teknol., 2016, 78(2-2):49-56

[17] Gardner H, Hatch T. Multiple intelligence go to school: Educational implications of the theory of multiple intelligence. Educ. Reseacher, 1989, 18(8):4-10

[18]Hafidi M, Lamia M. A personalized adaptive e-learning system based on learner ' $\mathrm{s}$ feedback and learner' $\mathrm{s}$ multiple intelligences. In 12th International Symposium on Programming and Systems (ISPS), 2015, pp. 1-6.

[19]Sajjadi P, Vlieghe J, and De Troyer O. Evidence-based mapping between the theory of multiple intelligences and game mechanics for the purpose of player-centered serious game design. In VS-Games 2016, 8th Int. Conf. Games Virtual Worlds Serious Appl., 2016, pp. 1-8 [20]Siti Zulaiha A, Ariffin A M. Proposing the components of conceptual design model of ICAL4LA using comparative analysis method. J. Telecommun. Electron. Comput. Eng., 2016, 8(8): $1-6$

[21]Nurulnadwan A, Ariffin A M, and Siti Mahfuzah S. The design principles of assistive courseware for low vision (AC4LV) learners. ARPN J. Eng. Appl. Sci., 2015, 10(3): $1447-1456$

[22] Mackwoski M S, Brzoza P F, Spinczyk D R. Tutoring math platform accessible for visually impaired people. Computers in Biology and Medicine, In Press, 2017, 1-9

[23] Basciftci F, Eldem A. A third eye with human-computer interaction for the visually impaired. Computer \& Electrical Engineering, 2017, 59, 63-72

[24] Mattheiss E, Regal G, Sellitsch D, Tscheligi M. User-centred design with visually impaired pupils: A case study of a game editor for orientation and mobility training. International Journal of Child-Computer Interaction, 2017, 11, 12-18

\section{How to cite this article:}

Nurulnadwan A, Ariffin A M, and Siti Mahfuzah S. The development of assistive courseware for young low vision learners based on multiple intelligence theory. J. Fundam. Appl. Sci., 2017, 9(5S), 989-1005. 